\title{
Study of the Degradation of the Herbicide Clomazone in Distilled and in Irrigated Rice Field Waters using HPLC-DAD and GC-MS
}

\author{
Renato Zanella, ${ }^{*, a}$ Ednei G. Primel, ${ }^{b}$ Fábio F. Gonçalves, ${ }^{a}$ Manoel L. Martins, ${ }^{a}$ Martha B. Adaime, ${ }^{a}$ \\ Enio Marchesan ${ }^{c}$ and Sérgio L. O. Machado
}

${ }^{a}$ Departamento de Química, Universidade Federal de Santa Maria (UFSM), 97105-900 Santa Maria-RS, Brazil

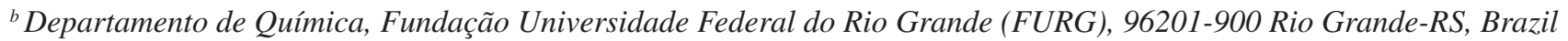

${ }^{c}$ Centro de Ciências Rurais, UFSM, 97105-900 Santa Maria-RS, Brazil

\begin{abstract}
Este estudo avaliou a degradação do herbicida clomazone em água destilada e de campos de arroz irrigado, através de irradiação UV e sob condições naturais. Após a etapa de pré-concentração por extração em fase sólida (SPE), a concentração remanescente foi determinada por cromatografia líquida de alta eficiência com detecção por arranjo de diodos (HPLC-DAD) e a identificação dos produtos de degradação foi efetuada por cromatografia gasosa com espectrometria de massas (GC-MS). Sob irradiação UV, o clomazone foi degradado mais rapidamente na água destilada que na água de superfície. Na água de irrigação, sob luz solar, o clomazone apresentou tempo de meia-vida médio de 3,2 dias em três safras consecutivas, e após a aplicação a concentração na água permaneceu acima de $0,1 \mu \mathrm{g} \mathrm{\textrm {L } ^ { - 1 }}$ por cerca de 20 dias. Diversos subprodutos, tais como 2-clorobenzaldeído e 2-clorobenzeno metanol, foram identificados por GC-MS, evidenciando que a concentração dos intermediários aumentou no início e então eles também sofreram degradação.
\end{abstract}

This study evaluated the degradation of the herbicide clomazone in distilled water and from irrigated rice fields, through UV irradiation and under natural conditions. After a solid phase extraction (SPE) as preconcentration step, the remained concentration of clomazone was determined by high performance liquid chromatography with diode array detection (HPLC-DAD) and the identification of the degradation products was achieved by gas chromatography-mass spectrometry (GC-MS). Under UV irradiation, the clomazone was degraded faster in distilled water than in surface water. In irrigated rice water, under sunlight irradiation, clomazone presented a half-life time average of 3.2 days in three consecutive harvests, and after application the concentration in water remained higher than $0.1 \mu \mathrm{g} \mathrm{L}^{-1}$ for 20 days. Several by-products, like 2-chlorobenzaldehyde and 2-chlorobenzene methanol, were identified by GC-MS, which evidenced that the concentration of intermediates at the begining increase and then they also undergo degradation.

Keywords: clomazone, degradation, HPLC-DAD, GC-MS, water

\section{Introduction}

Environmental water pollution by pesticides is a problem with widespread ecological consequences. ${ }^{1}$ Herbicides are potential contaminants of environmental water because they are directly applied to the soil or irrigating water. Thus, they can be leached to the surface water and transported into the groundwater. ${ }^{2,3}$ According to specialized literature, ${ }^{2,4}$ a pesticide can pollute the aquatic environmental if its solubility in water is higher than $30 \mathrm{mg} \mathrm{L}^{-1}$; its $\mathrm{K}_{\mathrm{oc}}$, organic

*e-mail: rzanella@base.ufsm.br carbon partition coefficient is less than 300-500; its $\mathrm{K}_{\mathrm{H}}$, Henry's Law constant is less than $10^{-2} \mathrm{~Pa} \mathrm{~m}^{3} \mathrm{~mol}^{-1}$, its soil half-life is longer than 2-3 weeks and its water half-life is longer than 25 weeks.

Clomazone, CAS number 81777-89-1, [2-[(2-chlorophenyl) methyl]-4,4-dimethyl-3isoxazolidinone] is widely used against species of annual broad leaf weeds and grass. Clomazone is currently used in the cultivation of soybeans, cotton, rice, sugar cane, corn, tobacco and a variety of other vegetable crops. ${ }^{5}$ It is stable at room temperatures for at least 2 years and it is also stable at $50^{\circ} \mathrm{C}$ for at least 3 months. Half-life time $\left(\mathrm{t}_{1 / 2}\right)$ with 
sunlight is $>30$ days in an aqueous solution and 30-135 days in soil. It is highly soluble in water $\left(1100 \mathrm{mg} \mathrm{L}^{-1}\right)$ and has a $\mathrm{K}_{\mathrm{oc}}$ of $150-562 \mathrm{~mL} \mathrm{~g}^{-1}$ and a $\mathrm{K}_{\mathrm{H}}$ value of $4.19 \times$ $10^{-3} \mathrm{~Pa} \mathrm{~m}^{3} \mathrm{~mol}^{-1}{ }^{6}$ These properties of clomazone indicate its potential for aquatic environmental pollution. In this study we selected clomazone because it is an important herbicide that has been detected in the majority of the water samples collected from rivers located close to irrigated rice fields in the South of Brazil. ${ }^{3}$

The major sources of pesticide pollution are wastewater from agricultural industries and pesticide formulating or manufacturing plants, and their removal from the aquatic environment has become a very important task and different methods are used including carbon adsorption, ozonization, microbial degradation, photodegradation, etc. Hydrolysis, photolysis, using natural sunlight or xenon arc lamps, aquatic metabolism and field dissipation can also contribute to degradation. ${ }^{7,8}$ In practice, the evaluation of degradation products is possible through identification by GC-MS. ${ }^{9}$

Therefore, today, the removal of organic harmful pollutants present in water supplies is investigated through a variety of chemical procedures. Among them, oxidation by several agents besides chlorine, such as ozone, UV radiation and Fenton's reagent, have been extensively and successfully used. ${ }^{9}$ The Advanced Oxidation Processes (AOPs), which are constituted by the combination of several oxidants, are characterized by the generation of very reactive and oxidizing free radicals in aqueous solutions, such as the hydroxyl radicals, which have a great destructive power. ${ }^{10}$ Many of them are currently employed in the elimination of pesticides, ${ }^{11,12}$ however no study has been published about procedures to degrade clomazone.

Photochemical reactions are especially important as a technique to remove harmful chemicals from the waste effluents. Photochemical decomposition of pesticides represents an important transformation pathway that can occur in surface waters. ${ }^{13}$ Photochemical AOPs are light induced reactions, mainly oxidations that rely on the generation of hydroxyl radicals through combination with added oxidants (e.g. $\mathrm{H}_{2} \mathrm{O}_{2}, \mathrm{Fe}^{3+}$ ).

For the determination of herbicides in water samples the high performance liquid chromatography with diode array detection (HPLC-DAD), after a solid phase extraction (SPE) as preconcentration step, is frequently employed. ${ }^{14}$

The objectives of this work were $i$ ) to compare the kinetic degradation of clomazone in distilled and surface water by using a high-pressure mercury lamp; ii) to investigate the $\mathrm{pH}$ influence on photodegradation; iii) to identify the photodegradation products and $i v$ ) to follow the degradation in the field under natural conditions. The concentration of clomazone was determined by
HPLC-DAD as described in Zanella et al. ${ }^{5}$ and the identification of the photodegradation products was obtained by GC-MS.

\section{Experimental}

\section{Instrumentation}

The HPLC-DAD analyses were performed with a Varian (Palo Alto, USA) 9002 pump, a Rheodyne (Cotati, CA, USA) 7125 six-port valve with $20 \mu \mathrm{L}$ loop, and a Varian ProStar 335 diode array detector. The separation was performed on a $250 \times 4.6 \mathrm{~mm}$ i.d., $5 \mu \mathrm{m}$ particle, Bondesil C18 analytical column from Varian, operated at room temperature. The mobile phase was methanol-water 65:35 (v/v) adjusted to $\mathrm{pH} 4.0$ with phosphoric acid. It was prepared from separated measured volumes of methanol and water and was degassed for $15 \mathrm{~min}$ in an ultrasonic bath before use. The flow-rate was set at $1.0 \mathrm{~mL} \mathrm{~min}^{-1}$ and quantification was performed by detection at $220 \mathrm{~nm}$.

A Varian 3800 CX gas chromatograph with autosampler 8400 and Saturn 2000 mass spectrometer detector equipped with a CP-Sil 8CB-MS column of $30 \mathrm{~m}$ length, $0.25 \mathrm{~mm}$ i.d. and $0.25 \mu \mathrm{m}$ film thickness was used to identify the products of transformation. The following chromatographic conditions were used: injector temperature of $250{ }^{\circ} \mathrm{C}$, column oven temperature program of $45^{\circ} \mathrm{C}$, held for $1.5 \mathrm{~min}$, then a gradient of $10{ }^{\circ} \mathrm{C} \mathrm{min}^{-1}$ up to $260{ }^{\circ} \mathrm{C}$, maintained for more $4 \mathrm{~min}$. Helium was used as a carrier gas at a constant pressure of $10 \mathrm{psi}$, resulting in a flow-rate of $1 \mathrm{ml} \mathrm{min}$. The temperatures of the ion source and the interface were set at 250 and $290{ }^{\circ} \mathrm{C}$, respectively. The MS was operated in electron impact mode with a potential ionization of $70 \mathrm{eV}$ and the spectra were obtained at a scan range from $\mathrm{m} / \mathrm{z} 50$ to 650 (full scan mode). The scan time was 0.90 seconds and $1.0 \mu \mathrm{L}$ injections were made.

\section{Chemicals}

Clomazone standard (99.8\%) was obtained from Dr. Ehrenstorfer (Augsburg, Germany) and a commercial formulation Gamit ${ }^{\circledR} 500 \mathrm{CE}$, which contained $500 \mathrm{~g} \mathrm{~L}^{-1}$ of clomazone, was obtained on the market. Methanol of HPLC grade was from Mallinckrodt (Phillipsburg, NJ, USA). Phosphoric acid of analytical grade was from Merck (Darmstadt, Germany). Water was purified with a Milli-Q water purification system (Millipore, Bedford, MA, USA). The physicochemical characteristics of selected surface waters were: $\mathrm{pH} 6.5$; oxygen chemical demand $15.4 \mathrm{mg} \mathrm{L}^{-1}$ of $\mathrm{O}_{2}$; turbidimetry $22 \mathrm{UT}$; real color $10 \mathrm{mg} \mathrm{L}^{-1}$ of Pt; total 
alkalinity $8.7 \mathrm{mg} \mathrm{L}^{-1}$ of $\mathrm{CaCO}_{3}$; total solids $110 \mathrm{mg} \mathrm{L}^{-1}$. The extraction tubes were Bakerbond SPE octadecyl C18 (3 mL, $200 \mathrm{mg}$ ) from J. T. Baker (Phillipsburg, NJ, USA).

\section{Photodegradation experiments and SPE preconcentration} step

The employed homemade reactor apparatus consisted of a tank reactor with a capacity of $2 \mathrm{~L}$ and equipped with magnetic stirring, a system for measuring and controlling the reaction temperature, and a high-pressure mercury lamp of $125 \mathrm{~W}$. All photodegradation experiments were carried out at room temperature $\left(25^{\circ} \mathrm{C}\right)$ in the reactor containing $1.5 \mathrm{~L}$ of water spiked at $5 \mathrm{mg} \mathrm{L}^{-1}$ of clomazone level using a commercial formulation. Different $\mathrm{pH}$ values (3.0 and 6.0) and different water matrices (distilled and surface water) were tested.

After the treatment, an aliquot of the water sample $(50 \mathrm{~mL})$ was removed from the reactor and preconcentrated in a solid phase extraction (SPE) system. The SPE column was conditioned by the consecutive passage of $3 \mathrm{~mL}$ methanol, $3 \mathrm{~mL}$ Milli-Q water, $3 \mathrm{~mL}$ Milli-Q water at $\mathrm{pH}$ 3.0 (adjusted with phosphoric acid 1:1, v/v). The samples were passed through the SPE column under vacuum at $5 \mathrm{~mL} \mathrm{~min}{ }^{-1}$. Immediately after that, the column was washed with $3 \mathrm{~mL}$ Milli-Q water, the eluate was discarded, and the adsorbent bed was dried under vacuum for $2 \mathrm{~min}$. After drying, the analyte was eluted with $1 \mathrm{~mL}(2 \times 500 \mu \mathrm{L})$ methanol and analyzed by HPLC-DAD and GC-MS.

\section{Study of the degradation of herbicides in irrigated rice farming water}

The samples of farming water were collected from four experimental fields, with $4 \times 4 \mathrm{~m}$ each, of rice crops of the Crop Science Department at the Campus of the Federal University of Santa Maria (UFSM). The commercial product Gamit ${ }^{\circledR} 500 \mathrm{EC}$ was used for the application of clomazone at $500 \mathrm{~g} \mathrm{ha}^{-1}$ level, resulting, with a water level of $10 \mathrm{~cm}$, in an initial concentration of $500 \mu \mathrm{g} \mathrm{\textrm {L } ^ { - 1 }}$. The samples were collected on days $1,2,3,5,7,10,14,21,28$, 35 and 45 after the application of the herbicide in the period between November and March of 2000-2001, 2001-2002 and 2002-2003. The calculation of the degradation was performed using the first-order rate equation: ${ }^{7}$

$-\ln \left[\mathrm{C}_{\mathrm{t}}\right] /\left[\mathrm{C}_{\mathrm{o}}\right]=\mathrm{k} \times \mathrm{t}$

where $\mathrm{C}_{\mathrm{t}}$ represents the concentration at time $\mathrm{t}$; $\mathrm{C}_{\mathrm{o}}$ represents the initial concentration; and $\mathrm{k}$ is the degradation constant, obtained by the slope of the straight line. When the concentration is reduced to $50 \%$ of the initial amount, the half-life time $\left(\mathrm{t}_{1 / 2}\right)$ can be determined by:

$\mathrm{t}_{1 / 2}=0.693 / \mathrm{k}$

\section{Results and Discussion}

\section{Photodegradation of clomazone}

For all collected samples, an increase in the degradation of clomazone and of the products were observed in the systems HPLC-DAD and GC-MS, respectively. From the results of the degradation in different water types after UV irradiation (Table 1), it was observed that in distilled water a larger degradation of the herbicide occurs when compared with surface water using an irradiation time up to $120 \mathrm{~min}$. That probably occurs due to the turbidity of the surface water samples, which reduces the penetration of the UV radiation. It was also observed that in distilled water there is not a great influence of the $\mathrm{pH}$ on the degradation rate. However, the surface water samples at $\mathrm{pH} 3.0$ present a larger degradation than at $\mathrm{pH}$ 6.0. This can be explained by the occurrence, at $\mathrm{pH} 3.0$, of the Photo-Fenton process to some degree, being that the surface water presents a concentration of iron to the order of $1 \mathrm{mg} \mathrm{L}^{-1}$. The dissolved organic substances present in surface water can induce a reduction of the degradation rate. ${ }^{15}$

Table 1. Remaining clomazone concentration $\left(\mathrm{mg} \mathrm{L}^{-1}\right)$ in distilled and surface water at $\mathrm{pH} 3.0$ and 6.0 after different irradiation time*

\begin{tabular}{lcccc}
\hline Irradiation & \multicolumn{2}{c}{ Distilled water } & \multicolumn{2}{c}{ Surface water } \\
time / $(\mathrm{min})$ & $\mathrm{pH} \mathrm{3.0}$ & $\mathrm{pH} \mathrm{6.0}$ & $\mathrm{pH} \mathrm{3.0}$ & $\mathrm{pH} \mathrm{6.0}$ \\
\hline 0 & 4.98 & 4.98 & 4.95 & 4.96 \\
5 & 4.13 & 3.49 & 4.34 & 4.64 \\
10 & 3.36 & 1.82 & 3.80 & 3.81 \\
15 & 2.88 & 1.43 & 2.95 & 3.49 \\
30 & 0.90 & 0.56 & 2.00 & 2.29 \\
45 & 0.24 & 0.31 & 1.22 & 1.50 \\
60 & 0.08 & 0.09 & 0.53 & 0.52 \\
90 & & & 0.26 & 0.22 \\
120 & & & 0.09 & \\
\hline
\end{tabular}

* Number of replicates, for each degradation experiment, $n=3$.

Figure 1 shows the HPLC-DAD chromatograms obtained from fortified distilled and surface water samples adjusted to $\mathrm{pH} 3.0$ after exposure to UV radiation for 0 , 30 and $60 \mathrm{~min}$.

Table 2 shows the results obtained for the kinetics of the photodegradation of clomazone at different $\mathrm{pH}$ values (3.0 and 6.0) for distilled and surface water.

The degradation constant $\mathrm{k}$ was obtained from the slope of the curve ln (C) versus time (Figure 2). The 

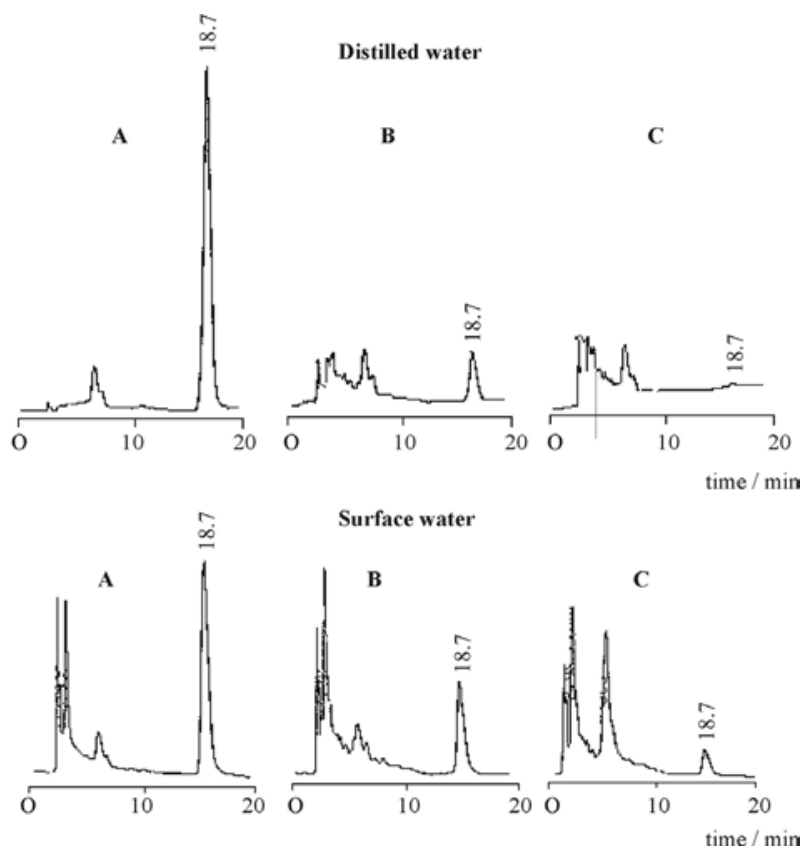

Figure 1. HPLC-DAD chromatograms obtained from fortified $\left(5 \mathrm{mg} \mathrm{L}^{-1}\right)$ distilled and surface water at $\mathrm{pH} 3.0$ after exposure to UV radiation for: A) 0 ; B) 30 and C) $60 \mathrm{~min}$. $\mathrm{t}_{\mathrm{R}}$ clomazone $=18.7 \mathrm{~min}$.

photodegradation for surface water at $\mathrm{pH} 3.0$ was more efficient when compared to the sample at $\mathrm{pH} 6.0$, both presenting kinetics of degradation of the first order. The coefficients $r^{2}$ are in general high indicating that the degradation curves fit the data. The results obtained allowed us to conclude that the photodegradation process, proposed for the clomazone herbicide in water samples, is simple and efficient.
Table 2. Kinetics of photodegradation of clomazone in water*

\begin{tabular}{|c|c|c|c|c|}
\hline Water samples & & $\begin{array}{c}\text { Reaction } \\
\text { order }\end{array}$ & $\mathrm{k} /\left(\min ^{-1}\right)$ & $\mathrm{t}_{1 / 2} /(\min )$ \\
\hline \multirow[t]{2}{*}{ Distilled water } & $\mathrm{pH} 3.0$ & 1 & $0.0720 \pm 0.002$ & $9.7 \pm 0.28$ \\
\hline & $\mathrm{pH} 6.0$ & 1 & $0.0629 \pm 0.002$ & $11.0 \pm 0.33$ \\
\hline \multirow[t]{2}{*}{ Surface water } & $\mathrm{pH} 3.0$ & 1 & $0.0336 \pm 0.0009$ & $20.7 \pm 0.57$ \\
\hline & $\mathrm{pH} 6.0$ & 1 & $0.0358 \pm 0.0007$ & $19.4 \pm 0.37$ \\
\hline
\end{tabular}

* Number of replicates, for each degradation experiment, $n=3$.

\section{Degradation of herbicides in irrigated rice farming water}

Figure 3 shows that after the first week of application the clomazone concentration remains high $\left(198 \mu \mathrm{g} \mathrm{L}^{-1}\right.$ in the 2000-01 harvests; $292 \mu \mathrm{g} \mathrm{L}^{-1}$ in the 2001-02 harvests, and $86 \mu \mathrm{g} \mathrm{L}^{-1}$ in the 2002-03 harvests), residues being found up to the fourth week $\left(1.3 ; 0.75\right.$ and $7.8 \mu \mathrm{g} \mathrm{L}^{-1}$ in the 2000-01; 2001-02 and 2002-03 harvests, respectively). Thus, the results indicate that the water should be maintained in the irrigation fields for at least 28 days, before being released to the environment. This is very important, since studies conducted with fishes had demonstrated short-term effects of exposure to environmentally relevant concentrations of clomazone on AChE activity in brain and muscle tissue. ${ }^{16,17}$

Clomazone presented a half-life time, obtained using equation 2 , of $3.1,3.4$ and 3.2 days in the field experiment, in the 2000-01; 2001-02 and 2002-03's harvests, respectively. Analyzing the results obtained from the samples of farming water, it can be concluded that the clomazone herbicide

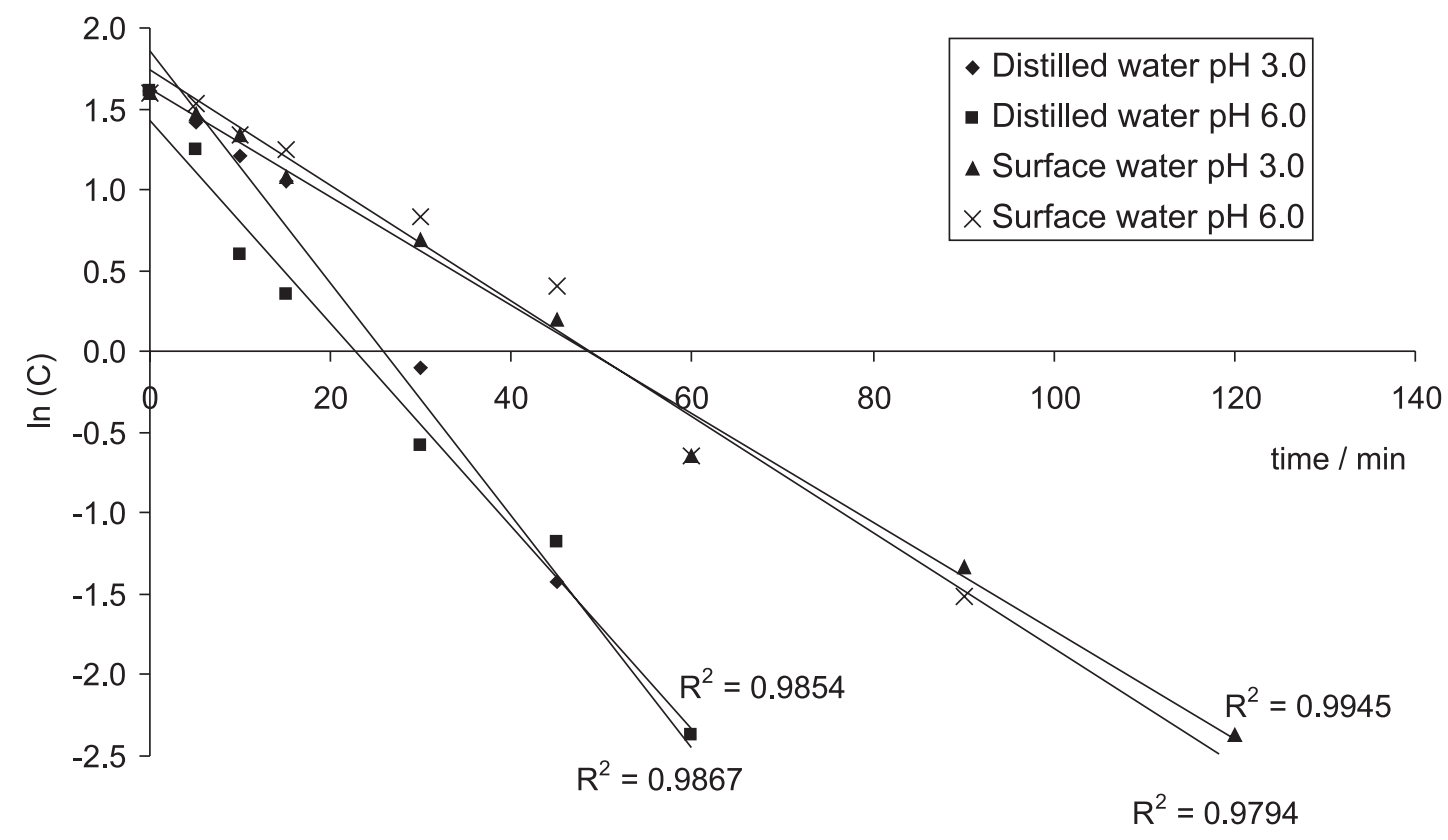

Figure 2. First order rate plots for degradation of water samples, containing $5.0 \mathrm{mg}$ clomazone $\mathrm{L}^{-1}$, irradiated up to $60 \mathrm{~min}$ for distilled water, and up to $120 \mathrm{~min}$ for surface water. 


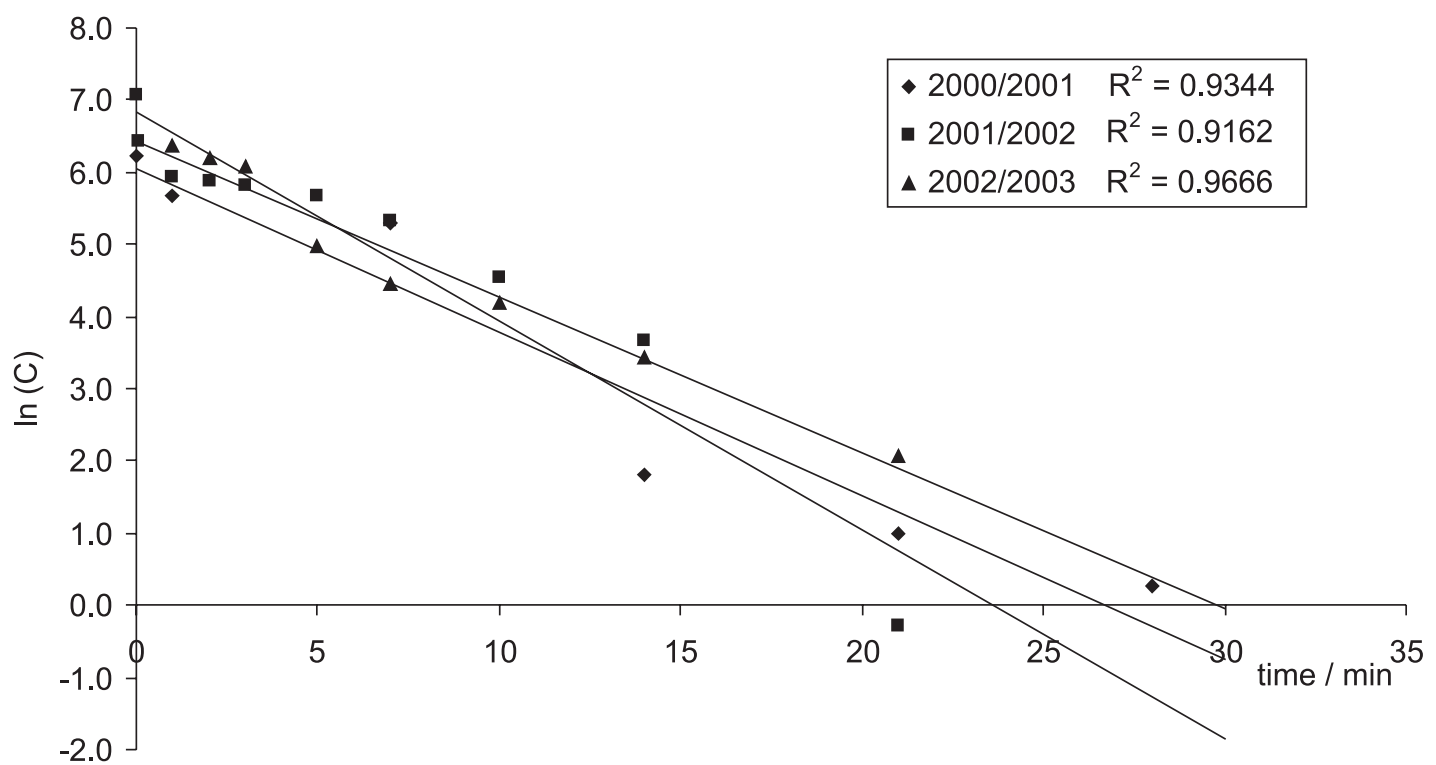

Figure 3. Profile of the degradation of clomazone in irrigated rice farming water. Equations: harvest 2000/2001: $y=-0.2062( \pm 0.0037) x+6.4501( \pm 0.1925)$, harvest 2001/2002: $y=-0.1063( \pm 0.0318) x+6.7601( \pm 0.6854)$ and harvest $2002 / 2003: y=-0.096( \pm 0.0070) x+6.1348( \pm 0.1159)$.

is quite persistent, because its half-life time average is 3.2 days.

\section{Degradation products identified by $G C-M S$}

In order to investigate the disappearance of clomazone observed by HPLC-DAD analysis, the SPE extracts of samples of distilled water adjusted to $\mathrm{pH} 3.0$, spiked at 5 $\mathrm{mg} \mathrm{L}^{-1}$ using a commercial formulation of clomazone and irradiated by UV light at the same conditions of the test were analyzed by GC-MS. The profile of this disappearance is very similar to that obtained by HPLC-DAD, however with GC-MS the total disappearance of the clomazone signal is observed only at $120 \mathrm{~min}$. The GC-MS data confirm the experimental results obtained by HPLC-DAD, that is to say, a fast degradation of the clomazone by UV radiation, presenting a kinetic reaction described by an equation of the first order.

The preconcentration of 50 times allowed the identification of the formed products, especially of the most polar compounds that only produce signals in GC-MS at high concentrations. The use of a silanized liner, a column of low polarity and an SPI injector allowed the observation of some more polar compounds that presented well resolved chromatographic signals. The degradation profiles for the main byproducts (2-chlorobenzaldehyde and 2-chlorobenzene methanol), as well as for clomazone, are demonstrated in Figure 4 , and both exhibit a regular increase followed by a decrease as expected for the first major degradation products.
Figure 5 presents GC-MS chromatographic signals, data points, spectra, masses and fragmentation suggested for clomazone and identified by-products. The used mass spectrometer, with a scan rate of $5600 \mathrm{~m} / \mathrm{z}$ by second, allowed to obtain enough data points by signal. Each data point represents the average of three acquisitions of the spectra of masses of 50 to $650 \mathrm{~m} / \mathrm{z}$ providing improved spectral quality.

\section{Identification of the compounds}

Table 3 presents the data of the detected and confirmed compounds by the GC-MS technique. The evolution, represented by the respective peak area, of clomazone and intermediates formed during the photodegradation treatment indicate a progressive disappearance of clomazone. For the degradation products an initial concentration increase occurred and then they are also degraded.

\section{Clomazone}

The fragments of larger intensity are the $\mathrm{m} / \mathrm{z}, 240$ (molecular ion) this only being observed due to a high injected concentration. The ion $\mathrm{m} / \mathrm{z} 204$ formed by the loss of the atom of chlorine and the $m / z, 125$, that according to the suggested fragmentation outline is formed by the breakage of the molecule of clomazone at the carbon bound with nitrogen, and the consequent loss of the $-\mathrm{C}_{5} \mathrm{H}_{8} \mathrm{NO}_{2}$ of $\mathrm{m} / \mathrm{z}$ 114. In comparison with the library NIST98, clomazone (CAS 81777-89-1) presented a spectral fit greater than $85 \%$ with the spectrum of the library. As we used a commercial 
<smiles>CC(C)C(=O)N1OCC(C)(C)C1=O</smiles><smiles>N#Cc1ccccc1Cl</smiles><smiles>Oc1ccccc1Cl</smiles>

M.W. $=129$

M.W. $=137$

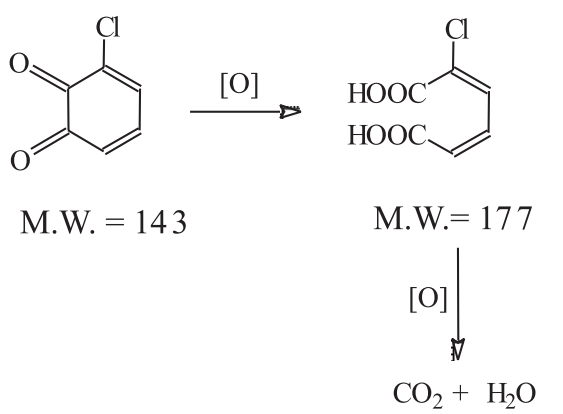

Figure 4. Possible degradation pathways proposed for clomazone. For the compounds 1 to $\mathbf{6}$ identified by GC-MS the observed molecular weight was shown. For the others, the calculated mass (considering the most common isotope) was shown.

formulation and the preparation of the sample involved an extraction stage in C18 cartridges, we presented the interpretation of the spectrum of clomazone to demonstrate the capacity of the equipment and of the analytical process of producing the characteristic spectrum for the compound in the conditions of the experiment.

\section{2-Chlorobenzaldehyde}

It is formed in the degradation process by the cleavage of the $\mathrm{C}-\mathrm{N}$ bond of the carbon of the methyl group adjacent to the chlorinated aromatic ring, with the consequent liberation of the isoxazolidinone group that was not observed in any of the analyzed extracts. The fragmentation of the 2-chlorobenzaldehyde results the formation of fragments with mass/charge $(\mathrm{m} / \mathrm{z})$ relations of 139 and 111 . The fragment with $\mathrm{m} / \mathrm{z}, 139$ corresponds to the molecular ion and the fragment of $\mathrm{m} / z 111$ corresponds to the loss of the $-\mathrm{COH}$ group. In comparison with the library NIST98 this compound presented a spectral fit of $90 \%$ with the spectrum regarding to 2-chlorobenzaldehyde (CAS 89-98-5). 

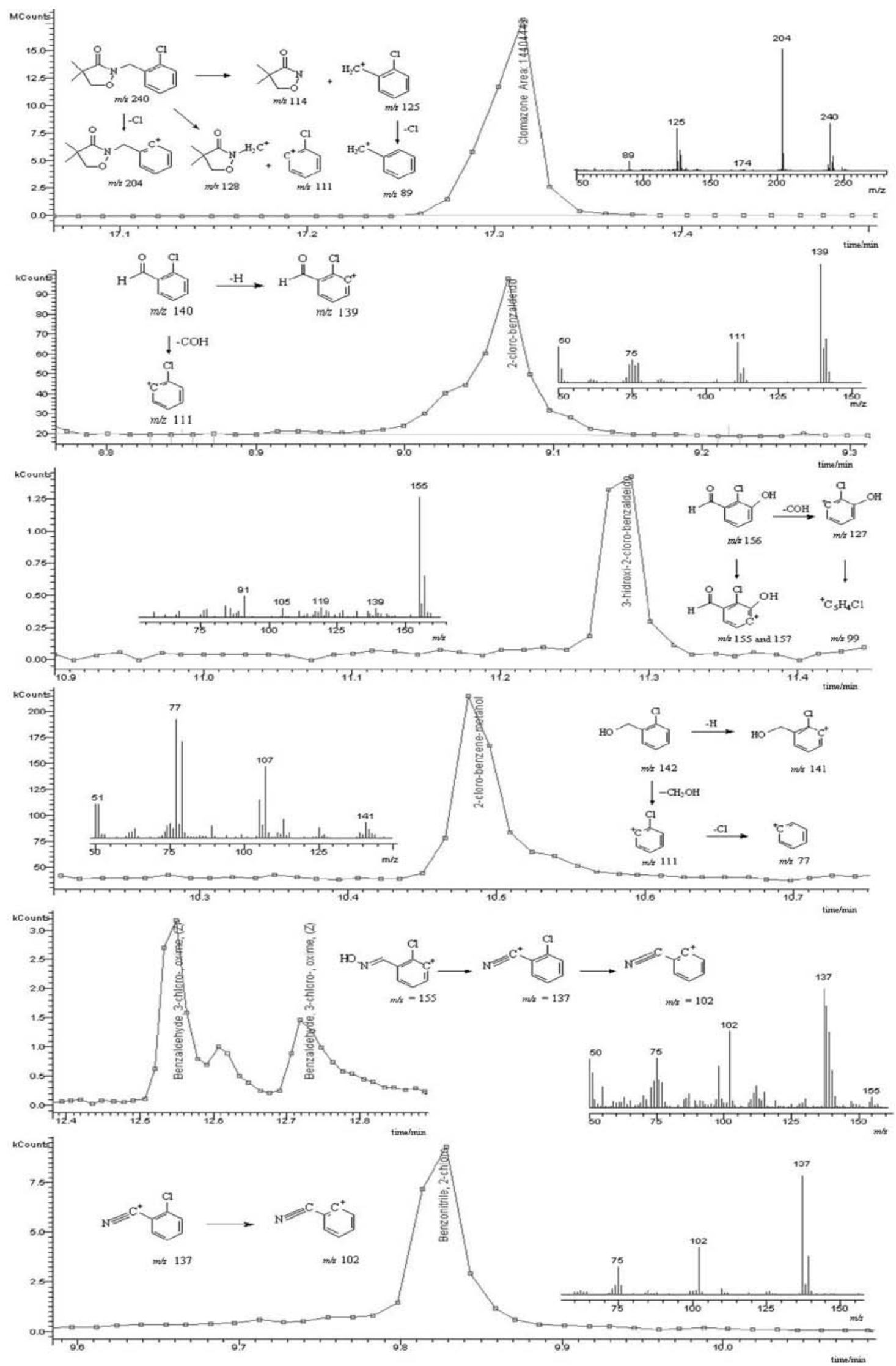

Figure 5. Chromatographic signals, datapoints, spectra, masses and fragmentation suggested for clomazone and identified by-products. 
Table 3. Evolution of clomazone and intermediates formed during the photodegradation

\begin{tabular}{|c|c|c|c|c|c|c|c|c|}
\hline MW & 239 & 140 & 156 & 142 & 155 & 137 & & \\
\hline CAS RN & $81777-89-1$ & $104-88-1$ & $56962-11-9$ & $17849-38-6$ & $3717-33-7$ & $623-03-0$ & & \\
\hline $\mathrm{t}_{\mathrm{R}} /(\min )$ & 17.31 & 8.88 & 11.28 & 10.49 & 9.82 & 12.72 & & \\
\hline $\mathrm{m} / \mathrm{z}$ fragment & 204,125 & 139,111 & $\begin{array}{c}155,139 \\
111,91\end{array}$ & $\begin{array}{c}142,141 \\
107,77\end{array}$ & $\begin{array}{c}155,137 \\
102\end{array}$ & $\begin{array}{c}137,102 \\
75\end{array}$ & & \\
\hline \multirow{2}{*}{ time /(min) } & \multicolumn{6}{|c|}{ Peak area of the compounds } & Total peak & Area reduction / $\%$ \\
\hline & 1 & 2 & 3 & 5 & 6 & 7 & area & Area reauction/\% \\
\hline 0 & $48,550.654$ & 64.673 & - & 208.626 & - & - & $48,823.953$ & - \\
\hline 5 & $47,427.893$ & 187.342 & - & 433.942 & 123.097 & 53.730 & $49,373.874$ & 0 \\
\hline 10 & $34,821.315$ & 588.836 & 11.734 & 529.321 & 130.992 & 125.806 & $35,410.850$ & 20.0 \\
\hline 15 & $34,841.694$ & 635.608 & 10.802 & 534.365 & 79.511 & 140.729 & $36,022.469$ & 18.6 \\
\hline 30 & $33,578.809$ & 541.301 & 6.485 & 549.604 & 147.126 & 218.823 & $34,676.199$ & 21.7 \\
\hline 45 & $20,924.670$ & $1,507.085$ & - & 347.740 & 70.077 & 103.176 & $22,779.495$ & 48.5 \\
\hline 60 & $7,739.352$ & $1,732.896$ & - & 252.952 & 97.986 & 166.072 & $9,725.200$ & 78.0 \\
\hline 90 & 846.828 & 852.114 & - & 39.843 & 39.389 & 44.294 & $1,738.785$ & 96.1 \\
\hline 120 & 101.110 & 215.278 & - & - & 18.980 & - & 316.388 & 99.3 \\
\hline
\end{tabular}

1 = clomazone; 2 = 2-chloro-benzaldehyde; 3 = 3-hidroxy-2-chloro-benzaldehyde; 5 = 2-chloro-benzene-methanol; 6 = benzaldehyde, 3 -chloro-oxime and 7 = benzonitrile-4-chloro.

\section{3-Hydroxy-2-chloro-benzaldehyde}

It is formed by the hydroxylation of 2-chlorobenzaldehyde. The main formed fragments presented $\mathrm{m} / \mathrm{z}$ ratios of $155,157,127$ and 99 . The fragments $m / z, 155$ and $\mathrm{m} / \mathrm{z} 157$ correspond to the molecular ion, and the fragment of $\mathrm{m} / \mathrm{z} 157$ comes with an intensity corresponding to $32.8 \%$ of the fragment of $\mathrm{m} / \mathrm{z} 155$ due to the natural isotopic abundance of the chlorine atom present in the molecule. The fragment of $m / z 127$ is formed by the loss of the group - $\mathrm{COH}$. The fragment of $\mathrm{m} / \mathrm{z}, 99$ is formed by the loss of one more carbon and one oxygen atom. In comparison to the library NIST98 these compounds presented spectral fit greater than $70 \%$ with the spectrum regarding 3-hydroxy2-chloro-benzaldehyde (CAS 56962-10-8). In spite of the small areas in relation to those observed in other compositions, it is important to observe that the formation of this composition indicates the attack by the hydroxyl radical formed by the effect of irradiation with UV light.

\section{2-Chloro-benzene-methanol}

It can be formed by the reduction of the 2-chlorobenzaldehyde or by attack of the hydroxyl radical in the moment of the breakage of the $\mathrm{C}-\mathrm{N}$ bond. In the fragmentation of the 2-chloro-benzene-methanol the fragments of $\mathrm{m} / \mathrm{z}, 142$ and 141 are observed, respectively the molecular ion and the molecular ion less one $\mathrm{H}$ atom. The ion with $\mathrm{m} / \mathrm{z} 111$ is formed by the loss of the $-\mathrm{CH} 2 \mathrm{OH}$, resulting in the protonated fragment formed by the aromatic ring linked to the chlorine. The loss of the atom of chlorine for this fragment generates the ion with $\mathrm{m} / \mathrm{z} 77$ also observed in the mass spectrum. In comparison with the library NIST98 this compound presented spectral fit greater than $85 \%$ with 2-chloro-benzenemethanol (CAS 17849-38-6).

\section{Benzaldehyde, 2-chloro-oxime}

Forming the fragments of $m / z 155,137$ and 102. The fragment $\mathrm{m} / \mathrm{z} 155$ corresponds to the molecular ion, and the 157 indicates the presence of a chlorine atom. The fragment of $m / z 137$ corresponds to the loss of the hydroxyl by the benzaldehyde, 3-chloro-oxime, also being observed a signal with $m / z$ of $138,139,140$ and 141 formed by the presence of $\mathrm{N}$ and $\mathrm{Cl}$ in the structure. It is also observed a peak with $\mathrm{m} / \mathrm{z} 102$ indicating the loss of the chlorine from the previous fragment. Comparing with the library NIST98, this compound presented spectral fit greater than $90 \%$ with the benzaldeyhde-3-chloro-oxime (CAS 4006-79-5). In the chromatogram two close signals were observed with $t_{R}$ between 12.5 and 12.6 min presenting this same characteristic spectrum, which should correspond to the isomer compounds $\mathrm{Z}$ and $\mathrm{E}$. In the conditions used in the experiment, the identification by GC-MS doesn't allow to distinguish between the isomeric position, like benzaldehyde, 3-chloro-oxime and benzaldehyde, 2-chlorooxime, that present the same mass spectrum.

\section{Benzonitrile-2-chloro}

Formed by the loss of the $\mathrm{OH}$ group by the 2-chlorooxime-benzaldehyde. The fragmentation formed the ion $\mathrm{m} / \mathrm{z} 137$ corresponding to the molecular ion and the ion with $\mathrm{m} / \mathrm{z} 102$ regarding loss of the chlorine. In the 
comparison with the library NIST98 this compound presented a spectral fit greater than $95 \%$ with the 2-chlorobenzonitrile (CAS 873-32-5).

The acquisition of the data was performed using a scan range from $\mathrm{m} / \mathrm{z}, 50$ to 650 in order to see if it would not form by-products with larger molecular weight than clomazone for mono- or dihydroxylation or aggregate formation ${ }^{18,19}$ and to verify other pollutants that could be introduced in the samples in the irradiation processes and extraction.

Using only irradiation the hydroxylation reaction in clomazone does not occur, but rather the breakage of the molecule. Since the products formed in the reaction also disappeared, we believe that the mechanism followed the path of formation of carboxylic acids, which is quite important since this follows the natural path for biological metabolization of organic compounds. A suggestion of the reaction pathway from an environmental perspective is presented in Figure 4.

\section{Conclusion}

The obtained information allows a better understanding of the behavior of the herbicide clomazone in distilled and surface waters. The proposed photodegradation process enables an efficient degradation of clomazone in water. The reversed-phase HPLC with DAD detection has proven to be efficient to show the decrease of clomazone during the treatments at the field and in the laboratory. Application of GC-MS for identification and confirmation of clomazone and intermediates formed during the photodegradation treatment increases the reliability of the chromatographic follow up. The evolution of clomazone and intermediates indicate a progressive disappearance of clomazone. For the degradation products an initial increase occurred and then they were degraded. The GC-MS results permit to suggest a degradation pathway for clomazone from an environmental perspective.

\section{Acknowledgments}

The authors would like to thank Brazilian agencies FAPERGS, CNPq and CAPES for financial support and fellowships.

\section{References}

1. Chiron, S.; Fernandez-Alba, A.; Rodriguez, A.; Garcia-Calvo, E.; Water Res. 2000, 34, 366.

2. Hatrík, S.; Tekel, J.; J. Chromatogr. A 1996, 733, 217.

3. Zanella, R.; Primel, E. G.; Machado, S. L. O.; Gonçalves, F. F.; Marchezan, E.; Chromatographia 2002, 55, 573.

4. Dores, E. F. G. C.; De-Lamonica-Freire, E. M.; Quim. Nova 2001, 24, 27.

5. Zanella, R.; Primel, E. G.; Gonçalves, F. F.; Martins, A. F.; J. Chromatogr. A 2000, 904, 257.

6. Tomlin, C. D. S.; The e-Pesticide Manual, $13^{\text {th }}$ ed. CDROM version 3.0, The British Crop Protection Councill: Farnham, UK, 2003.

7. Penuela, G. A.; Barceló, D.; J. Chromatogr. A 1998, 823, 81.

8. Penuela, G. A.; Barceló, D.; J. Chromatogr. A 1998, 795, 93.

9. Aguera, A.; Fernandez-Alba, A. R.; Analusis 1998, 26, M123.

10. Chiron, S.; Rodriguez, A.; Fernandez-Alba, A. R.; J. Chromatogr. A 1998, 823, 97.

11. Lanyi, K.; Dinya, Z.; Microchem. J. 2005, 80, 79.

12. Baird, C.; Environmental Chemistry, $2^{\text {nd }}$ ed., Freeman and Company: New York, 1999.

13. Bachman, J.; Patterson, H. H.; Environ. Sci. Technol. 1999, 33, 874.

14. Tran, A. T. K.; Hyne, R. V.; Pablo, F.; Day, W. R.; Doble, P.; Talanta 2007, 71, 1268.

15. Sakkas, V. A.; Lampropoulou, D. A.; Albanis, T. A.; Chemosphere 2002, 48, 939.

16. Crestani, M.; Menezes, C.; Glusczak, L.; Miron D. S.; Spanevello, R.; Silveira, A.; Gonçalves, F. F.; Zanella, R.; Loro, V. L.; Chemosphere 2007, 67, 2305.

17. Miron, D. S.; Crestani, M.; Shettinger, R. M; Morsch, V. M.; Baldisserotto, B.; Tierno, M. A.; Moraes, G.; Vieira, V. L.; Ecotoxicol. Environ. Saf. 2005, 61, 398.

18. Sims, G. K.; Mervosh, T. L.; Stoller, E. W.; J. Agric. Food Chem. 1995, 43, 537.

19. Rosazza, J. P. N.; Yu Liu, S.; Shocken, M.; J. Agric. Food Chem. 1996, 44, 313 